\title{
Reaction Rate Analysis of Manganese Ore Prereduction in $\mathrm{CO}-\mathrm{CO}_{2}$ Atmosphere
}

\author{
TRINE ASKLUND LARSSEN, DIETER SENK, and MERETE TANGSTAD
}

\begin{abstract}
Variations in energy efficiency and climate gas emissions in production of manganese ferroalloys are largely related to the solid-state reduction of the manganese ores used as raw material in the production. The gas-solid reduction is known to be dependent on the ore characteristics, making information on the factors governing the kinetics crucial. A reaction rate analysis of thermogravimetric data obtained for the reduction of Comilog and Nchwaning manganese ores in $\mathrm{CO}-\mathrm{CO}_{2}$ atmosphere was performed. Experimental variables were $\mathrm{CO}$ partial pressure, ore particle size, temperature regimes (isothermal/non-isothermal), as well as heating rate for non-isothermal experiments. The effects of particle size, $\mathrm{CO}$-concentration, and temperature on the reaction rates were quantified. It was found that the reduction rate of both ores was proportional to the inverse average particle size. Different sensitivities towards the $\mathrm{CO}$-concentration in the gas feed was determined, where the rate of Comilog-ore was proportional to $p_{\mathrm{CO}}^{0.7}$, and Nchwaning to $p_{\mathrm{CO}}^{1.5}$. The activation energy of Comilog ore was estimated to be $17 \mathrm{~kJ} / \mathrm{mol}$, whereas $63 \mathrm{~kJ} / \mathrm{mol}$ was found for Nchwaning ore.
\end{abstract}

https://doi.org/10.1007/s11663-021-02162-1

(C) The Author(s) 2021

\section{BACKGROUND}

OPTIMIZING low-temperature behavior in the production of manganese ferroalloys is an important issue with the potential of large energy savings, as well as reduction of gas emissions. Variations in carbon and energy consumption primarily arise from the gas-solid reactions occurring at relatively low temperatures, where the main contributor is the reduction of higher manganese (and iron) oxides by CO-gas. These variations are largely attributed to the occurrence of the Boudouard reaction $\left(\mathrm{C}+\mathrm{CO}_{2}=2 \mathrm{CO}\right)$, which is both carbon- and energy-consuming. The Boudouard reaction gains significant rates at temperatures exceeding $800^{\circ} \mathrm{C}$ in a ferromanganese furnace, and the reaction extent is dependent on the degree of ore reduction which occurs at this temperature range, as this will be the source of reactant $\mathrm{CO}_{2}$. The reduction of manganese ores in $\mathrm{CO}-\mathrm{CO}_{2}$ atmosphere is complex due to multistep, parallel, and exothermic reaction schemes. Kinetics and mechanisms of the prereduction of manganese ore is

TRINE ASKLUND LARSSEN is with the Norwegian University of Science and Technology (NTNU), 7034 Trondheim, Norway and also with the SINTEF, 7034 Trondheim, Norway. Contact e-mail: trine.a.larssen@sintef.no DIETER SENK is with the RWTH Aachen University, 52062 Aachen, Germany. MERETE TANGSTAD is with the Norwegian University of Science and Technology (NTNU).

Manuscript submitted November 25, 2020; accepted March 25, 2021.

Article published online April 29, 2021. dependent on the properties of the ore, and as such, numerous studies have been reported on the reduction behavior of various manganese materials. ${ }^{[1-5]}$ In spite of this, the behavior of the ores in the industrial furnace is not well understood. Reported non-isothermal reduction studies have generally been used to simulate the industrial practice by evaluating if the ores will continue to reduce in the active region of the Boudouard reaction, commonly defined as temperatures exceeding $800^{\circ} \mathrm{C}$. The ores are heated in reducing atmosphere and analysed for their oxygen content at the given target temperature, commonly $800{ }^{\circ} \mathrm{C}$ to $1000^{\circ} \mathrm{C} \cdot{ }^{[2,5-8]}$ These studies do generally not focus on kinetics and mechanisms. However, they have shown that ores with higher initial oxygen levels $\left(\approx \mathrm{MnO}_{2}\right)$ tend to have a lower oxygen content at $800^{\circ} \mathrm{C}$ compared to medium level oxygen ores $\left(\approx \mathrm{Mn}_{2} \mathrm{O}_{3}\right) \cdot{ }^{[2,5,7]}$ Further, Turkova et al. indicated a relationship between the ores initial porosity and the amount of oxygen remaining at $800{ }^{\circ} \mathrm{C},{ }^{[5]}$ where oxidized ores are found to generally exhibit a higher porosity. The reactivity at a given temperature has also been observed to be affected by particle size and heating rate, ${ }^{[7]}$ however the effect is yet to be quantified.

Studies reporting on kinetics and mechanisms have all been conducted in isothermal temperature regimes at fairly high temperatures. Kinetic data in $\mathrm{CO}-\mathrm{CO}_{2}$ atmosphere have been obtained for precalcined ores, ${ }^{[1,3,4,9]}$ where calcination decomposed initial oxides to $\mathrm{Mn}_{2} \mathrm{O}_{3}$ or $\mathrm{Mn}_{3} \mathrm{O}_{4}$. Berg ${ }^{[9]}$ investigated precalcined single particles of BHP (Groote Eylandt), ASM (Wessels), and NAM (Namibian) ore at $900{ }^{\circ} \mathrm{C}$ to $1100{ }^{\circ} \mathrm{C}$. A 
product layer was observed to be formed in the initial stages of the reduction. Hence, Berg utilized the shrinking core model to describe the experiments, which successfully described certain experiments, however appeared to be inadequate for a large quantity of the data. Nucleation and growth were found to be the governing mechanism during reduction of calcined unspecified ore by Gao et al., ${ }^{[4]}$ which was deduced from the model-fitting approach. It was suggested by the authors that the lack of topochemical reaction pattern was due to the small particle size, i.e. 105 to $150 \mu \mathrm{m}$. Ishak ${ }^{[3]}$ investigated the reduction of $\mathrm{Mn}_{3} \mathrm{O}_{4}$ to $\mathrm{MnO}$ in calcined Comilog ore at $900{ }^{\circ} \mathrm{C}$ to $1100{ }^{\circ} \mathrm{C}$. As the reaction rate was dependent on temperature and particle size, Ishak assumed that the reaction was controlled by both diffusion and chemical reaction. The results were modelled by both the shrinking core model and the grain model. Ishak further showed that the structure (porosity and surface area) of the solid reactant varied with preparation of the material. It was seen that experiments conducted with prereduced ore showed a reaction rate considerably higher compared to precalcined ore. This has also been observed by others. ${ }^{[2,10,11]}$ This suggests that kinetics obtained for calcined material may not be representative for manganese ores in an industrial furnace. Studies have also been reported on reduction of manganese ores in hydrogen atmosphere, which may be comparable to $\mathrm{CO} / \mathrm{CO}_{2}$ atmosphere. From isothermal reduction of synthetic pyrolusite in hydrogen at temperature range $200{ }^{\circ} \mathrm{C}$ to $500{ }^{\circ} \mathrm{C}$, Barner and Mantell claimed that the reduction proceeded topochemically through sequence $\mathrm{MnO}_{2}-\mathrm{M}$ $\mathrm{n}_{2} \mathrm{O}_{3}-\mathrm{Mn}_{3} \mathrm{O}_{4}-\mathrm{MnO} .^{[10]}$ The proposed mechanism was based on observations of oxides by XRD in combination with the reaction rate curves. From Arrhenius plots, it was suggested that there was a change in mechanism at $250{ }^{\circ} \mathrm{C}$ to $325{ }^{\circ} \mathrm{C}$ due to the formation of a less porous $\mathrm{Mn}_{3} \mathrm{O}_{4}$ product layer. The study briefly mentioned a significantly higher reduction rate observed in a Belgian Congo pyrolusite ore compared to the synthetic pyrolusite. De Bruijn et al. concluded that the isothermal reduction of an Indonesian $\mathrm{MnO}_{2}$ ore to $\mathrm{MnO}$ in hydrogen at temperatures $275^{\circ} \mathrm{C}$ to $400{ }^{\circ} \mathrm{C}$ was a two-step reduction, as only negligible amounts of $\mathrm{Mn}_{2} \mathrm{O}_{3}$ was found. ${ }^{[11]}$ It was suggested that the initial stages of the reduction follow the crackling core model, whereas latter stages followed the shrinking core model. It was further found that calculated activation energies for a specific reaction were dependent on starting material and its method of preparation.

The literature review shows that investigations on manganese ore reduction have mainly been performed on synthetic or calcined material, which have been observed to exhibit dissimilar reduction behavior compared to untreated ore. Further, the studies have often been conducted at fairly high temperatures, close to the melting point of the ores. As such, information on how the ore behaves at low temperatures is scarce.

This study aims to analyse the reduction rates of manganese ores without subjecting it to any pretreatment at temperature range $25^{\circ} \mathrm{C}$ to $1000{ }^{\circ} \mathrm{C}$. The paper presents the development of a kinetic equation by utilizing experimental data obtained during reduction of manganese ores in $\mathrm{CO}-\mathrm{CO}_{2}$ atmosphere. The work may be viewed as a continuation of the work presented by Larssen $e t a l .{ }^{[12]}$ regarding the reduction behavior of Comilog- and Nchwaning-ore. The mentioned study focused on the reduction products rather than the kinetics.

\section{EXPERIMENTAL}

Comilog and Nchwaning ore were reduced in $\mathrm{CO}-\mathrm{CO}_{2}$ atmosphere in isothermal and non-isothermal temperature regimes. The chemical composition of the ores is shown in Table I, showing that Comilog is a high oxygen ore with oxidation level ( $\mathrm{x}$ in $\mathrm{MnOx}$ ) equal to $1.92\left(\approx \mathrm{MnO}_{2}\right)$, whereas Nchwaning is a semi-oxidized ore with oxidation level equal to $1.47\left(\approx \mathrm{Mn}_{2} \mathrm{O}_{3}\right)$. The oxygen level of manganese was determined by titration (ASTM 465-11:2017), where excess oxygen relative to $\mathrm{MnO}$ is expressed as $\mathrm{MnO}_{2}$. Eltra (combustion-IR) was used to determine amount of carbon, which was recalculated to $\mathrm{CO}_{2}$. Remaining components were quantified by XRF. Characterization of these ores was recently performed and reported by Larssen et al. ${ }^{[12]}$ The main conclusions from mineralogy (XRD) and microstructure (SEM) studies will be summarized here. Comilog was mainly composed of $\mathrm{Mn}^{4+}$-oxides cryptomelane $\quad\left(\mathrm{KMn}_{8} \mathrm{O}_{16}\right)$, nsutite $\left(\mathrm{Mn}_{1-x}^{4+} \mathrm{Mn}_{x}^{2+} \mathrm{O}_{2-2 x}(\mathrm{OH})_{2 x}\right)$, and pyrosluite $\left(\mathrm{MnO}_{2}\right)$, whereas Nchwaning ore was mainly composed of various $\mathrm{Mn}^{3+}$-oxides bixbyite $\left(\mathrm{Mn}_{2} \mathrm{O}_{3}\right)$, braunite $\left(\mathrm{Mn}_{7} \mathrm{O}_{8} \mathrm{SiO}_{4}\right)$ and braunite II $\left(\mathrm{CaMn}_{14}\left(\mathrm{SiO}_{4}\right) \mathrm{O}_{20}\right)$, in addition to hematite $\left(\mathrm{Fe}_{2} \mathrm{O}_{3}\right)$ and calcite $\left(\mathrm{CaCO}_{3}\right)$. Microstructure investigations in SEM revealed a wide range of microstructure types in Comilog ore. Some showed homogeneous structures, appearing to be composed of a single mineral, whereas others contained several phases dispersed randomly throughout the particles. A third category of structures displayed a topochemical-like structure, where one mineral was present in the core, surrounded by an outer layer of a second mineral. Two distinct categories of structures were observed for Nchwaning ore, where one was composed of braunite II, and the other largely of braunite and carbonate. Hematite was found as a minor phase in both particles.

Non-isothermal experiments were conducted utilizing the facilities at Norwegian University of Science and Technology involving a vertical retort tube thermogravimetric furnace (Entech VTF 80/15). A schematic of the furnace may be found elsewhere. ${ }^{[13]}$ The sample is loaded into a steel crucible (height $45 \mathrm{~cm}$ and diameter $4.8 \mathrm{~cm}$ ) resting on a steel cage to ensure even gas distribution. The gas inlet is connected to the crucible lid, from which the gas travel through the double-walls before meeting the sample from below. The double walls thus enables preheating and premixing of the gas. The equipment set up includes a mass balance (Mettler Toledo PR2003DR, Switzerland) and an off-gas analyzer (NDIR), continuously measuring the $\mathrm{CO} / \mathrm{CO}_{2}$ 
Table I. Chemical Composition of Comilog and Nchwaning Ore (Size Fraction 11.20 to $15.00 \mathrm{~mm}$ )

\begin{tabular}{lccccccccc}
\hline & $\begin{array}{c}\mathrm{Fe}, \mathrm{tot} \\
\text { (Wt Pct) }\end{array}$ & $\begin{array}{c}\mathrm{Mn}, \mathrm{tot} \\
\text { (Wt Pct) }\end{array}$ & $\begin{array}{c}\mathrm{MnO}_{2} \\
\text { (Wt Pct) }\end{array}$ & $\begin{array}{c}\mathrm{MnO} \\
\text { (Wt Pct) }\end{array}$ & $\begin{array}{c}\mathrm{CaO} \\
\text { (Wt Pct) }\end{array}$ & $\begin{array}{c}\mathrm{SiO}_{2} \\
\text { (Wt Pct) }\end{array}$ & $\begin{array}{c}\mathrm{Al}_{2} \mathrm{O}_{3} \\
\text { (Wt Pct) }\end{array}$ & $\begin{array}{c}\mathrm{K}_{2} \mathrm{O} \\
\text { (Wt Pct) }\end{array}$ & $\begin{array}{c}\mathrm{CO}_{2} \\
\text { (Wt Pct) }\end{array}$ \\
\hline Comilog & 3.1 & 51.0 & 76.4 & 3.5 & 0.1 & 3.5 & 5.6 & 0.7 & 0.1 \\
Nchwaning & 10.0 & 46.4 & 34.6 & 31.6 & 5.9 & 6.7 & 0.5 & 0.0 & 3.0 \\
\hline
\end{tabular}

concentrations exiting the crucible. The furnace temperature is controlled by an Eurotherm PID controller in combination with a S-type thermocouple. Another S-type thermocouple in an alumina tube is inserted into the crucible, where its location is adjusted so that the hot junction is in the center of the solid sample.

$75 \mathrm{~g}$ of ore in particle size 0.50 to $1.36,3.33$ to 4.00 , 11.20 to 15.00 , and 30.00 to $40.00 \mathrm{~mm}$, was heated at 3 , 6 or $9^{\circ} \mathrm{C} / \mathrm{min}$ from room temperature up to target temperature of $1000{ }^{\circ} \mathrm{C}$. The standard experiments were conducted in 50 pct $\mathrm{CO}$ or 80 pct $\mathrm{CO}$ (remainder $\mathrm{CO}_{2}$ ), however 30 pct $\mathrm{CO}$ and 40 pct $\mathrm{CO}$ was also evaluated in order to determine the effect of $\mathrm{CO}$ partial pressure. All experiments were conducted with a total gas flow of 4 $\mathrm{Nl} / \mathrm{min}$. After target temperature was reached, the power supply was shut down and the furnace was lowered to down position, allowing the crucible to cool to ambient. The first 10 minutes of cooling was conducted with $4 \mathrm{Nl} / \mathrm{min}$ Argon flow, which subsequently was decreased to $1 \mathrm{Nl} / \mathrm{min}$ Argon for the remainder of the cooling. Some of the non-isothermal TGA data was also presented in a separate paper. ${ }^{[12]}$

Isothermal experiments were conducted at the facilities at IEHK RWTH Aachen. The specific apparatus was the Tammann furnace, which is an open thermogravimetric tube furnace. A schematic of the furnace is found elsewhere. ${ }^{[14]}$ The furnace was preheated to desired target temperature, in range $400{ }^{\circ} \mathrm{C}$ to $900{ }^{\circ} \mathrm{C}$, while flushed in $\mathrm{CO}_{2}$. Evaluated gas composition was 50 pet $\mathrm{CO}$ or 70 pet $\mathrm{CO}$ (remainder $\mathrm{CO}_{2}$ ) in a total gas flow of $3 \mathrm{Nl} / \mathrm{min}$, which was introduced when the target temperature was reached. Subsequently, 4 to 5 ore particles in size 11.20 to $15.00 \mathrm{~mm}$ (correlating to a total sample mass in range 18 to $25 \mathrm{~g}$ ) were loaded into a mesh sample holder made from tungsten wire and suspended from an electronic mass balance. Time and mass were recorded by a software connected to the mass balance at a 0.25 second interval. Following 20 to 60 min holding time, the samples were removed from the chamber and cooled in a separate container while flushed in argon.

Reduced samples were analysed in similar manner as the raw materials.

\section{REDUCTION BEHAVIOR}

\section{A. Comilog Ore}

Figure 1 shows the weight as a function of time and temperature, respectively, during heating of Comilog ore at $6{ }^{\circ} \mathrm{C} / \mathrm{min}$ up to $1000{ }^{\circ} \mathrm{C}$ in $\mathrm{CO}-\mathrm{CO}_{2}$ atmosphere at varying $\mathrm{CO}$-concentration. The sample temperature is affected by the exothermic reduction reactions, which causes the temperature to deviate from the prescribed heating program. The exothermic temperature peak gives rise to a "Z-shape" in the weight vs temperature curves. This behavior is characteristic for $\mathrm{MnO}_{2}$-ores. Further, it is seen that the reduction rate shows a low, but significant, dependency on the CO-concentration. From the reaction rate behavior, shown in Figure 2, it is seen that the reduction proceeds through several steps. It was shown by Larssen et al. ${ }^{[12]}$ that the reduction of Comilog ore initially proceeds as the overall reduction of $\mathrm{MnO}_{2}$ to $\mathrm{MnO}$, where a rapid reduction step is initiated at approximately $580{ }^{\circ} \mathrm{C}$. This was claimed to be the decomposition of any $\mathrm{MnO}_{2}$ present at this threshold temperature. The decomposition was confirmed in the present study by subjecting the ore to various heating rates. Figure 3(a) shows the temperature measurements of the furnace and the sample centre for the heating of Comilog ore in 50 pct $\mathrm{CO}$ to 50 pct $\mathrm{CO}_{2}$ at a heating rate of $3{ }^{\circ} \mathrm{C} / \mathrm{min}, 6^{\circ} \mathrm{C} / \mathrm{min}$, and $9{ }^{\circ} \mathrm{C} / \mathrm{min}$, respectively. The weight loss behaviour as a function of temperature is shown in Figure 3(b). It is seen that all experiments display a fast weight loss step when the temperature reaches $580{ }^{\circ} \mathrm{C}$ to $600{ }^{\circ} \mathrm{C}$, where the rapid weight loss step is merely affected by the amount of $\mathrm{MnO}_{2}$ remaining at the threshold temperature.

Larssen et al. ${ }^{[12]}$ investigated three particle size fractions, i.e. 0.50 to $1.36,3.33$ to $4.00 \mathrm{~mm}$, and 11.20 to $15.00 \mathrm{~mm}$. An additional particle size fraction, i. e. 30.0 to $40.0 \mathrm{~mm}$, was subjected to similar experimental conditions, where the reaction rate obtained for all four particle sizes is presented in Figure 4. The reaction rate of Comilog ore shows a clear dependency on the particle size. It is clear from Figure 4(b) that the temperature development of all particle sizes was affected by the exothermic reactions. The reduction of the two smaller particle sizes, i.e. 0.50 to $1.36 \mathrm{~mm}$ and 3.33 to $4.00 \mathrm{~mm}$, is completed at temperatures lower than the decomposition temperature of $\mathrm{MnO}_{2}$. As such, the reaction rate of these sizes displays an overall single step. This is not the case for the two larger particle sizes, where both 11.2 to $15.0 \mathrm{~mm}$ and 30.0 to $40.0 \mathrm{~mm}$ particles display a rapid increase in the rate at approximately $580{ }^{\circ} \mathrm{C}$. The magnitude of this peak depends on the amount of $\mathrm{MnO}_{2}$ present at this threshold temperature, resulting in a higher peak for particles of size 30.0 to $40.0 \mathrm{~mm}$ compared to 11.2 to $15.0 \mathrm{~mm}$.

It has previously been observed that the weight loss obtained during reduction of Comilog ore is a direct reflection of the change in oxidation level of manganese (x in MnOx) in the ore. ${ }^{[12]}$ The results are reprinted in Figure 5 for convenience. As such, obtained 


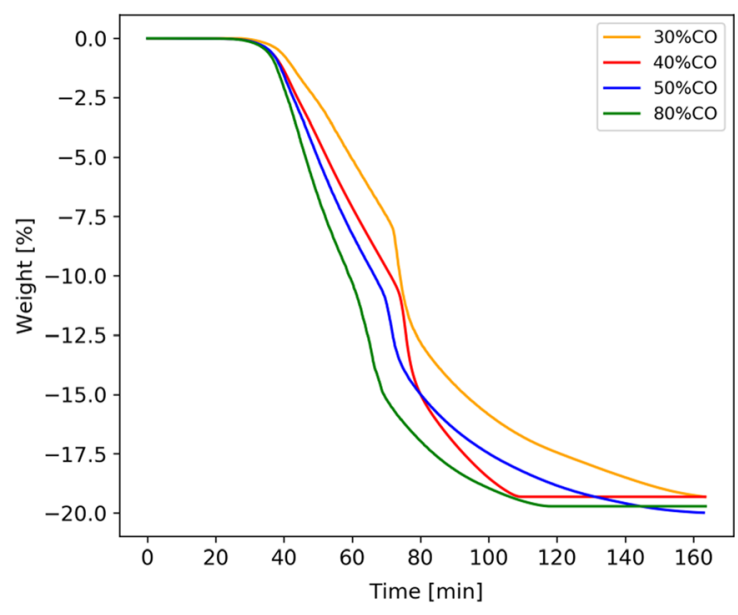

(a)

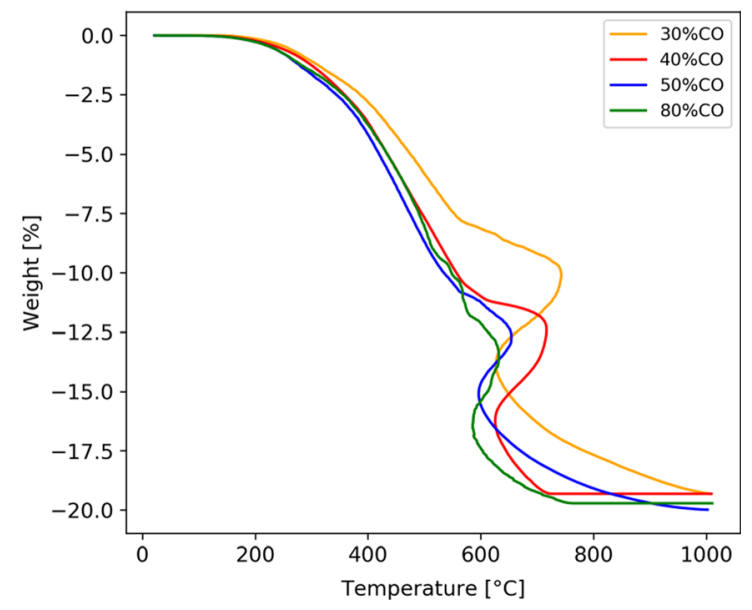

(b)

Fig. 1-Weight [pct] as a function of $(a)$ time and $(b)$ temperature for Comilog ore (11.2 to $15.0 \mathrm{~mm}$ particles) heated at $6{ }^{\circ} \mathrm{C} / \mathrm{min}$ in $\mathrm{CO}-\mathrm{CO}_{2}$ atmosphere with varying CO-concentration. TGA curves at 50 pet $\mathrm{CO}$ and $80 \mathrm{pct} \mathrm{CO}$ was retrieved from Larssen et al. ${ }^{[12]}$

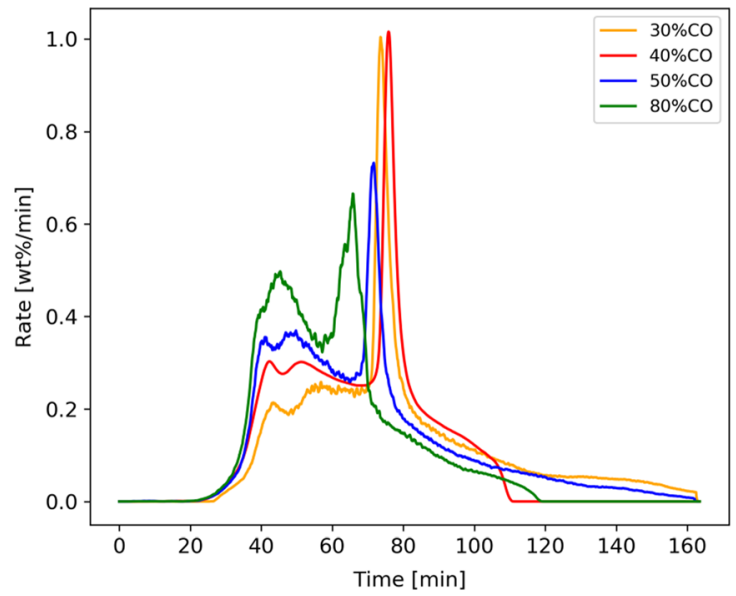

(a)

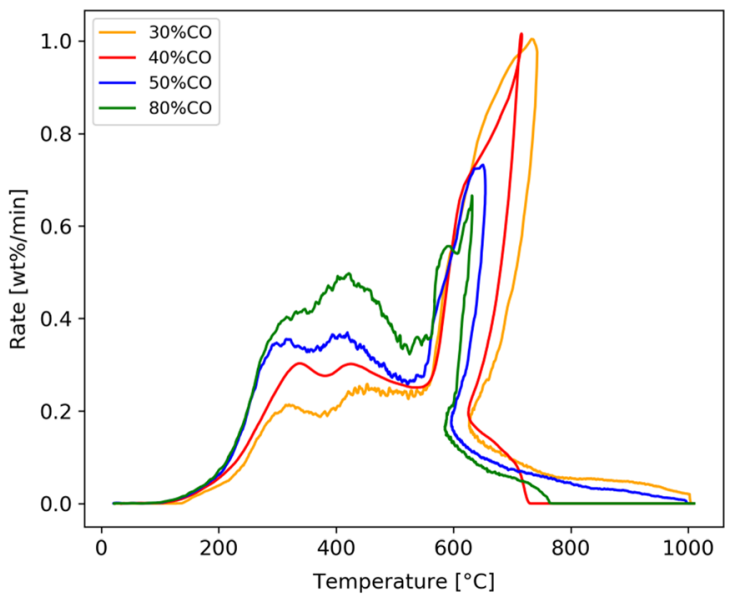

(b)

Fig. 2-Rate [wt pct/min] as a function of $(a)$ : time and $(b)$ temperature for Comilog ore $(11.2$ to $15.0 \mathrm{~mm}$ particles $)$ heated at $6{ }^{\circ} \mathrm{C} / \mathrm{min}$ in $\mathrm{CO}-\mathrm{CO}_{2}$ atmosphere with varying $\mathrm{CO}$-concentration. TGA curves at 50 pct $\mathrm{CO}$ and 80 pet $\mathrm{CO}$ was retrieved from Larssen et al. ${ }^{[12]}$

thermogravimetric data may be normalized to express the change in $\mathrm{MnOx}$, or a conversion extent between 0 and 1 .

Isothermal reduction experiments of 11.20 to 15.00 $\mathrm{mm}$ particles in $\mathrm{CO}-\mathrm{CO}_{2}$ atmosphere were conducted at RWTH Aachen. The conversion degree was calculated from the weight loss relative to the theoretical weight loss. The recorded weight and the calculated conversion curves for reduction in 50 to $50 \mathrm{CO}-\mathrm{CO}_{2}$ at temperatures $400{ }^{\circ} \mathrm{C}$ to $600{ }^{\circ} \mathrm{C}$ are seen in Figure 6. It is mentioned that decrepitation was observed to varying extent at all evaluated temperatures and holding times, however the curves presented here represent the experiments where all particles remained intact throughout the reduction course. It is seen that a higher reaction temperature correlates to a faster reaction rate. Experiments conducted at $400{ }^{\circ} \mathrm{C}$ showed large fluctuations and was thus not used to estimate kinetic parameters.

\section{B. Nchwaning Ore}

Weight as a function of time and temperature, respectively, for non-isothermal reduction of Nchwaning ore is shown in Figure 7. The corresponding reaction rate $[\mathrm{wt} \mathrm{pct} / \mathrm{min}]$ is shown in Figure 8 . The reaction rate behavior indicated that the reduction of Nchwaning ore is characterized by two main stages, where the two stages show varying extent of overlap depending on experimental conditions. The initial peak becomes less profound with increasing particle size, as well as 


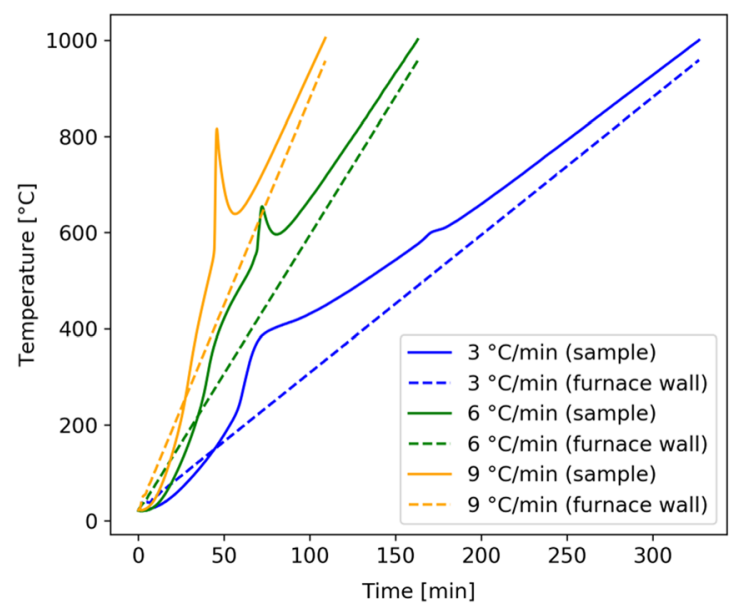

(a)

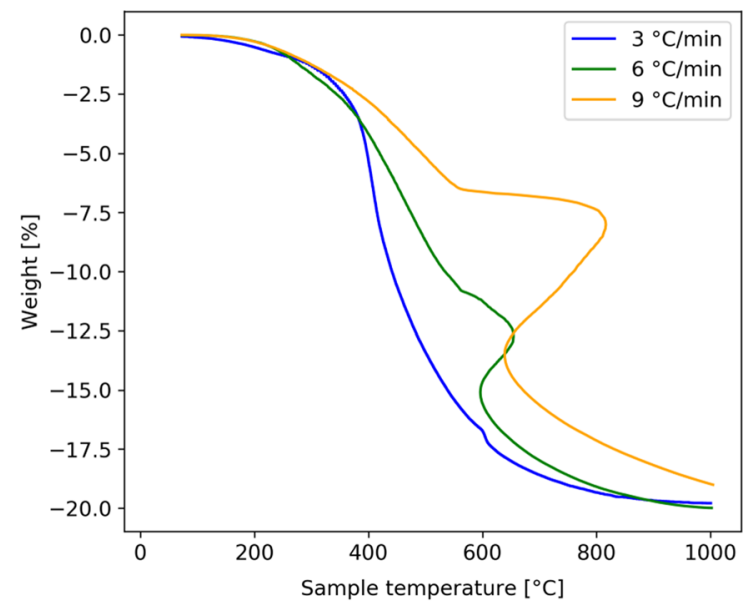

(b)

Fig. 3- (a) Temperature development as a function of time and $(b)$ weight as a function of sample temperature, for reduction of Comilog ore (11.20 to $15.00 \mathrm{~mm}$ ) at 3,6 , and $9{ }^{\circ} \mathrm{C} / \mathrm{min}$, respectively.

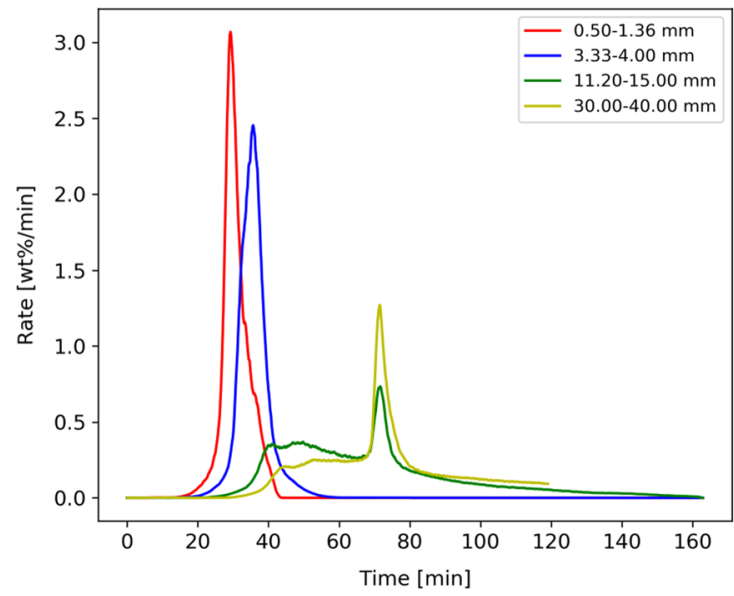

(a)

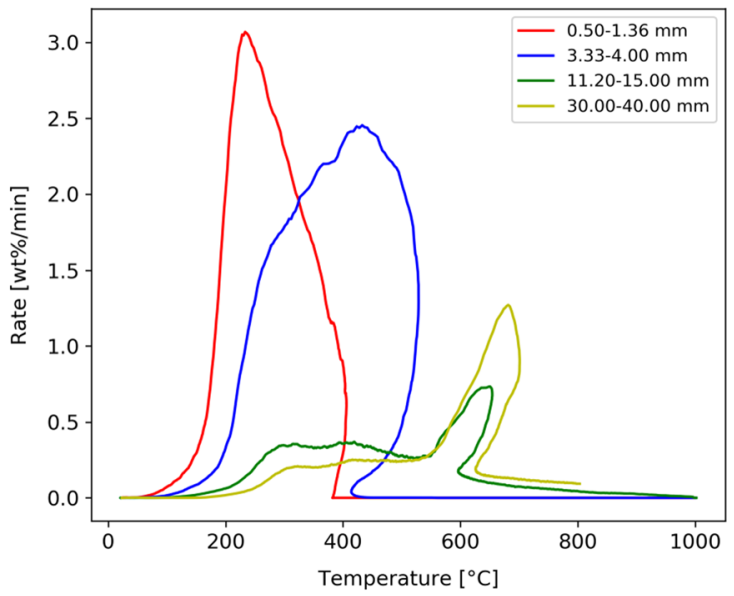

(b)

Fig. 4-Reaction rate [wt pct/min] as a function of $(a)$ time and $(b)$ temperature, respectively, for non-isothermal reduction of Comilog ore in

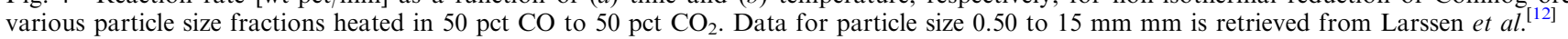

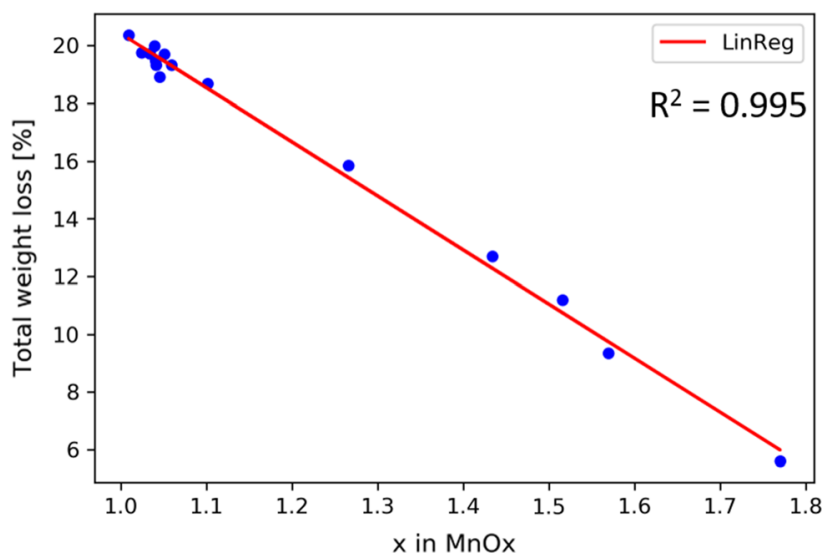

Fig. 5-Total obtained weight loss after heating in $\mathrm{CO}-\mathrm{CO}_{2}$ atmosphere as a function of analysed oxygen level of manganese $(x$ in $\mathrm{MnO} x$ ) for Comilog ore. Results reprinted from Larssen et al. ${ }^{[12]}$ decreasing $\mathrm{CO}$ partial pressure. The reproducibility of Nchwaning ore decreases with increasing particle size in the evaluated sample size. Parallels for 3.33 to $4.00 \mathrm{~mm}$ included in the figure shows high consistency between the duplicates. Data from particle size 30.00 to 40.00 $\mathrm{mm}$ heated in 50 pct $\mathrm{CO}\left(+\mathrm{CO}_{2}\right)$ up to $800{ }^{\circ} \mathrm{C}$ and $1000{ }^{\circ} \mathrm{C}$, respectively, is included in the figure, and it can be seen that the reduction behavior is relatively different between the two experiments that should be considered as parallels. The experiment terminated at $1000{ }^{\circ} \mathrm{C}$ shows a considerably higher reaction rate compared to the one terminated at $800{ }^{\circ} \mathrm{C}$. It is believed that this is due to decrepitation of the sample, thus decreasing the effective particle size. The sample terminated at $800{ }^{\circ} \mathrm{C}$ remained intact in the original particle size, whereas the sample terminated at $1000{ }^{\circ} \mathrm{C}$ had experienced intensive decrepitation. This indicates that the particle size highly influences the reaction rate of Nchwaning ore. Larger 


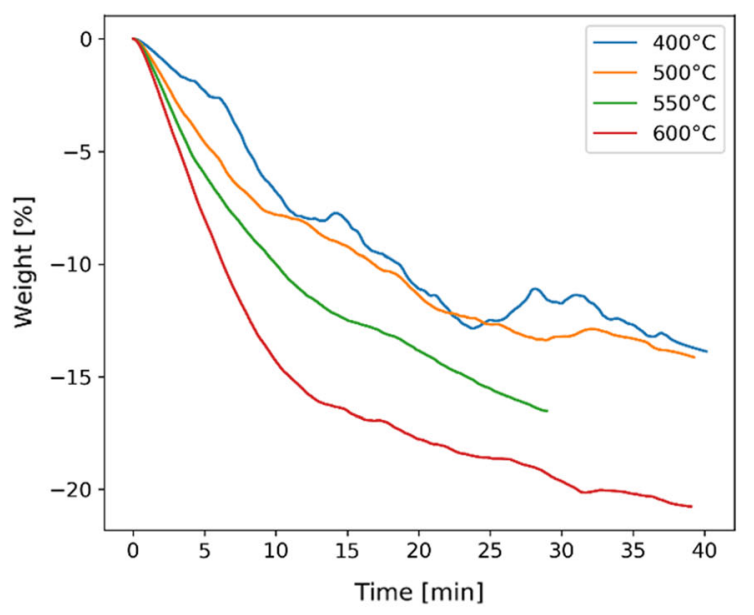

(a)

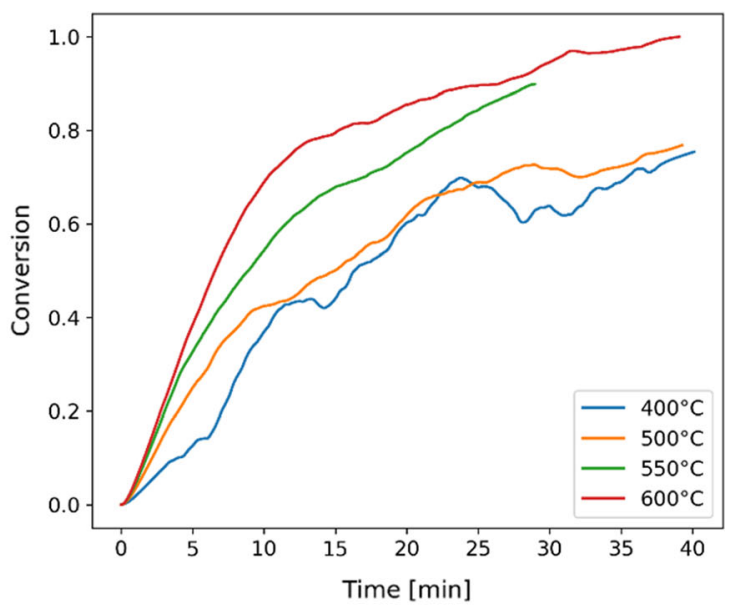

(b)

Fig. 6-Weight $(a)$ and calculated conversion $(b)$ as a function of holding time for isothermal reduction of Comilog ore.

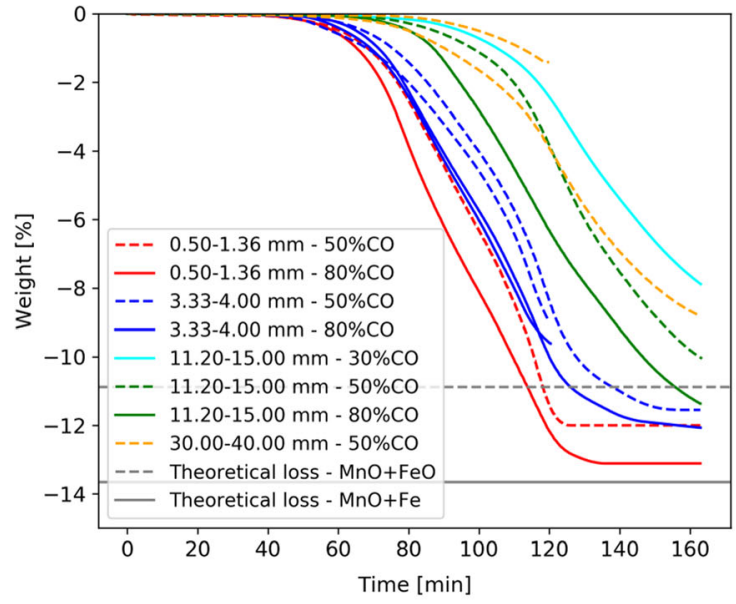

(a)

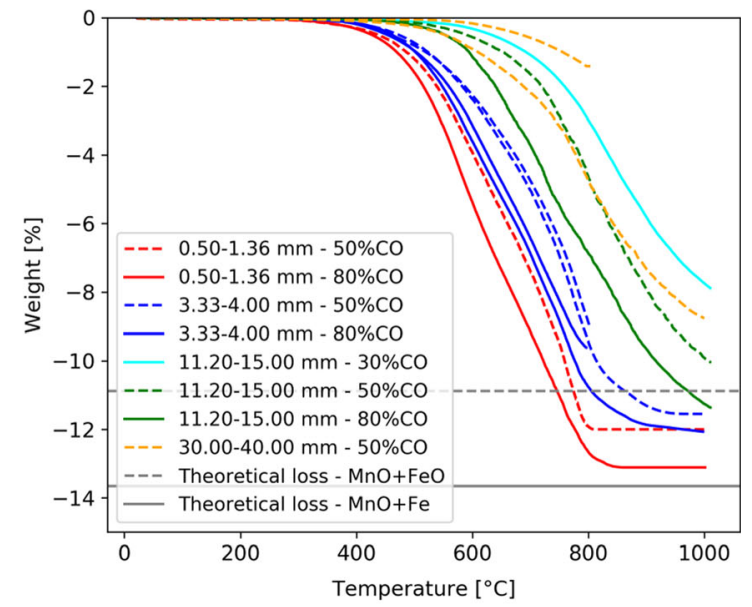

(b)

Fig. 7-Weight as a function of $(a)$ time and $(b)$ temperature, respectively, for non-isothermal $\left(6{ }^{\circ} \mathrm{C} / \mathrm{min}\right)$ reduction of Nchwaning ore. All data, except for 11.20 to $15.00 \mathrm{~mm}$ particles reduced in $30 \mathrm{pct} \mathrm{CO}$ and 30 to $40 \mathrm{~mm}$ particles, were retrieved from Larssen et al..$^{12]}$

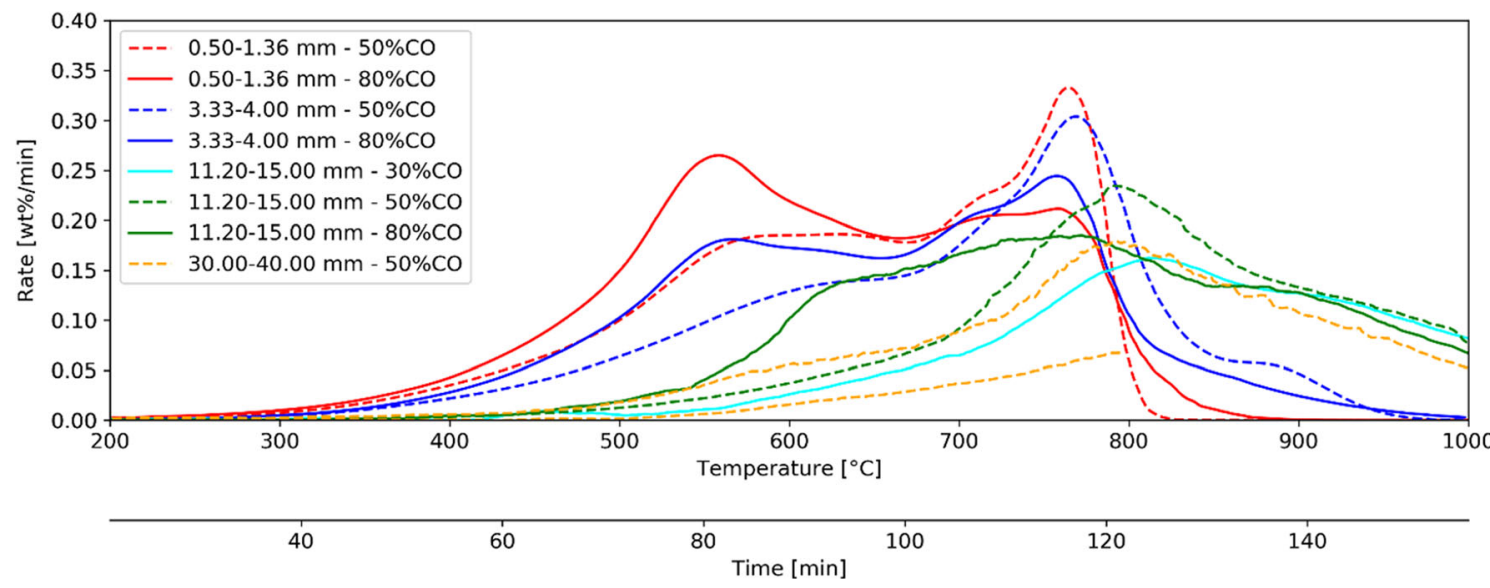

Fig. 8-Reaction rate curves (wt pct/min) for non-isothermal $\left(6^{\circ} \mathrm{C} / \mathrm{min}\right)$ reduction of Nchwaning ore. All data, except for 11.20 to $15.00 \mathrm{~mm}$ particles reduced in 30 pct $\mathrm{CO}$ and 30 to $40 \mathrm{~mm}$ particles, were retrieved from Larssen et al. ${ }^{[12]}$ 


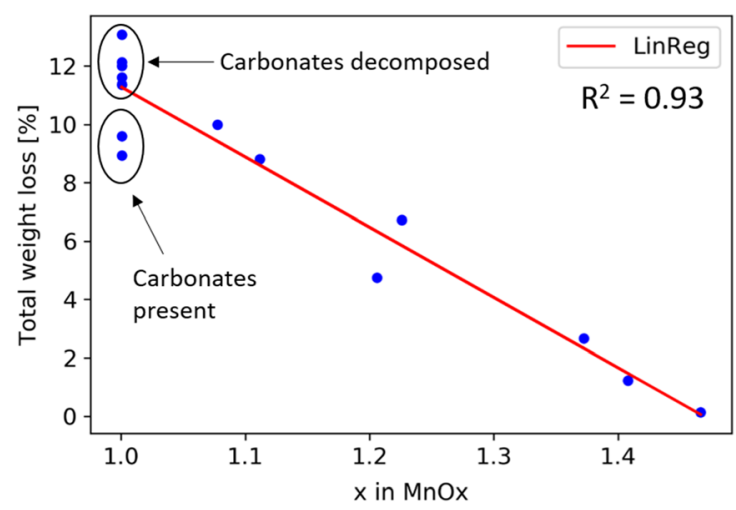

(a)

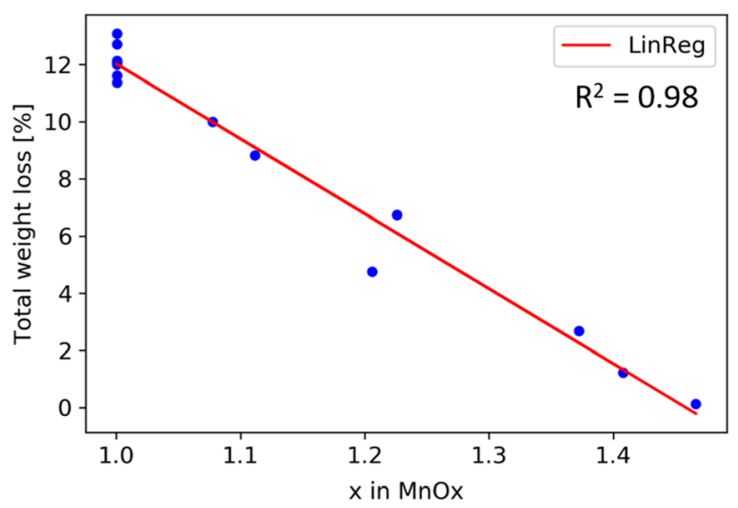

(b)

Fig. 9- Correlation between total obtained weight loss and analysed oxidation level of manganese ( $x$ in $\mathrm{MnO} x)$ for Nchwaning ore samples reduced non-isothermally in $\mathrm{CO}-\mathrm{CO}_{2}$ atmosphere. (a) Shows the raw data, where a difference between experiments terminated at $800{ }^{\circ} \mathrm{C}$ and $1000{ }^{\circ} \mathrm{C}$ was observed due to a difference in carbonate decomposition. In $(b)$ the weight loss due to carbonates have been included in the experiments terminated at $800{ }^{\circ} \mathrm{C}$. Chemical analysis retrieved from Larssen et al ${ }^{[12]}$

particles are more subjected to decrepitation, which may explain why the reproducibility of smaller particle sizes is higher compared to larger particle sizes.

Nchwaning ore contains $\mathrm{Mn}_{2} \mathrm{O}_{3}$-oxides, hematite and calcite. It was reported by Larssen et al. ${ }^{[12]}$ that the trivalent $\mathrm{Mn}$-oxides reduced to $\mathrm{MnO}$ in a single step, as the manganese was found distributed between $\mathrm{Mn}_{2} \mathrm{O}_{3}$ and $\mathrm{MnO}$ at all reduction extents. Considering the binary Fe-O system, metallic manganese could be obtained in $\mathrm{p}(\mathrm{CO})=0.8$, whereas the remaining atmospheres correlate to $\mathrm{FeO}$ as the stable iron phase. ${ }^{15]}$ Metallic iron was not detected in SEM nor in XRD analysis of any of the reduced samples, thus indicating that the reduction of hematite subsides with the formation of wustite $(\mathrm{FeO})$ in the evaluated conditions. The total obtained weight loss after reduction is shown as a function of the oxidation level of manganese ( $x$ in $\mathrm{MnO} x$ ) in Figure 9. Figure 9(a) shows the original data, where the weight loss correlating to an oxidation level of $1(\approx \mathrm{MnO})$ falls within two categories. The data points correlating to the lower weight losses were found from samples terminated at $800^{\circ} \mathrm{C}$, whereas the higher weight losses were obtained at $1000{ }^{\circ} \mathrm{C}$. It was found that this difference was due to the decomposition of carbonates, which occurred at 850 to $900{ }^{\circ} \mathrm{C}$. Figure 9(b) shows the correlation when the theoretical weight loss from carbonate decomposition has been included. A linear trend is found between the $x$ in $\mathrm{MnO} x$ and the overall weight loss. This indicates that the reduction of manganese and iron oxides may be assumed to be of similar magnitude throughout the reduction course.

Isothermal reduction experiments of 11.20 to 15.00 $\mathrm{mm}$ particles in $\mathrm{CO}-\mathrm{CO}_{2}$ atmosphere were conducted at RWTH Aachen. Figure 10 shows the weight behavior and the conversion degree for Nchwaning ore reduced isothermally in 50 pct $\mathrm{CO}$ to 50 pct $\mathrm{CO}_{2}$. The conversion degree was calculated from the recorded weight loss relative to theoretical weight loss. It is mentioned that decrepitation was observed to varying extent at all evaluated temperatures and holding times, however the curves presented here represent the experiments where all particles remained intact throughout the reduction course. An increasing reduction extent and reduction rate is observed with increasing temperature.

\section{REACTION RATE ANALYSIS}

Comilog- and Nchwaning-ore differ in both chemical and physical properties. Due to this, the ores show dissimilar reduction behavior when heated in reducing atmosphere. However, the previous chapters showed that the weight reduction of both Comilog- and Nchwaning-ore demonstrated a relatively linear correlation to the changing oxidation level of manganese ( $x$ in $\mathrm{MnO} x$ ). This implies that the overall reduction extent may be expressed through a reduction degree between 0 and 1. A reasonably well agreement was obtained between the non-isothermal reduction data for Comilogand Nchwaning-ore, respectively, and Eq. [1]. $\mathrm{d} X / \mathrm{d} T$ is the non-isothermal reaction rate $\left[\mathrm{min}^{-1}\right], k$ is the Arrhenius rate constant $[\mathrm{cm} / \mathrm{atm} \cdot \mathrm{min}], X$ is the conversion extent (reduction degree), $p_{\mathrm{CO}}$ is the $\mathrm{CO}$ partial pressure in the gas feed, and $r_{\mathrm{p}}$ is the average particle size in $\mathrm{cm}\left(\left(r_{1}+r_{2}\right) / 2\right)$. The values found for Comilog and Nchwaning have been summarized in Table II. The dependency on the CO partial pressure in the gas feed and the average particle size was determined from the apparent rate constants. The activation energy was estimated through simultaneous model-fitting of all available TGA data. 17 Comilog experiments and 14 Nchwaning ore experiments were used, where the experimental conditions included various $\mathrm{CO}$-concentration, various particle size, and varying heating rate. The agreement between the equation and some of the experimental data is shown in Figures 11 and 12 for Comilog ore and Nchwaning ore, respectively.

$$
\frac{\mathrm{d} X}{\mathrm{~d} T}=k(T(t)) \cdot(1-X) \cdot p_{\mathrm{CO}}^{m} \cdot r_{\mathrm{p}}^{n}
$$




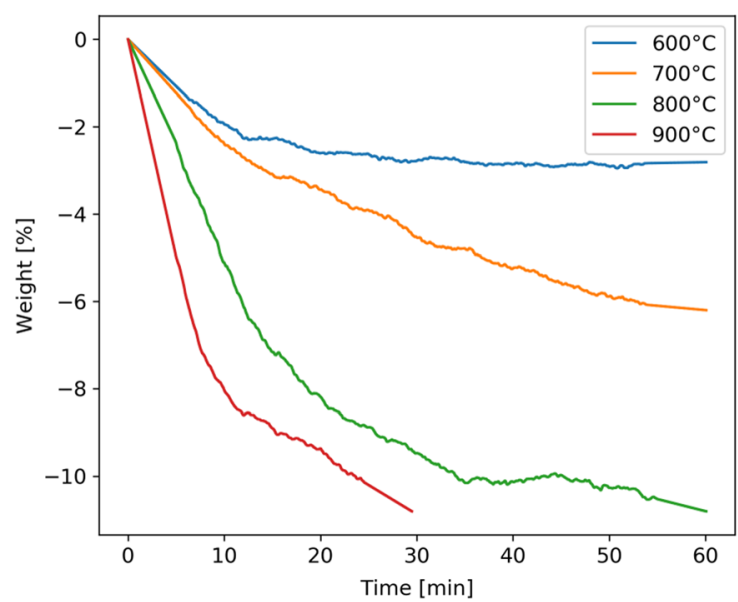

(a)

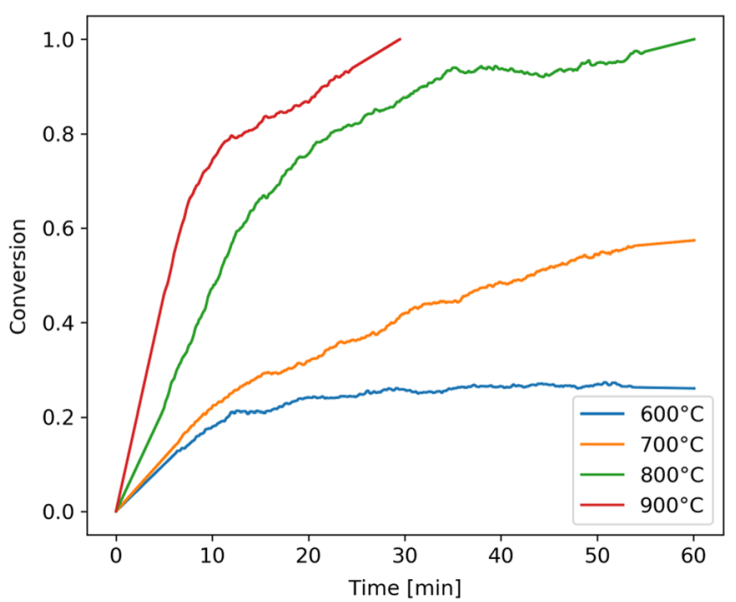

(b)

Fig. 10-Weight behavior $(a)$ and calculated conversion degree $(b)$ as a function of holding time for isothermal reduction of Nchwaning ore.

\section{A. Particle size}

TGA curves were obtained for four different particles sizes in 50 pct $\mathrm{CO}-50 \mathrm{CO}_{2}$ atmosphere, whereas three different sizes were evaluated in 80 pct $\mathrm{CO}$ to $20 \mathrm{pct}$ $\mathrm{CO}_{2}$. The effect of particle size on the reaction rates were determined by evaluating the apparent frequency factors as a function of the average particle size. This was performed by assuming that the reaction rate to be merely dependent on the rate constant and the extent of reduction. For Comilog ore in particle size $>11.20 \mathrm{~mm}$, the reduction data prior to the exothermic peak (correlating to the decomposition of $\mathrm{MnO}_{2}$ ) was utilized. Larger $(>11.20 \mathrm{~mm})$ particles of Nchwaning ore showed a linear correlation between the oxidation level of manganese and the total obtained weight loss. For smaller sizes, two distinct peaks were seen, which occurred at largely overlapping temperature ranges. Nchwaning ore appeared to be more heterogeneous in larger particle sizes, as a variation in the reduction behavior was observed between parallels. Mineralogy and microstructure investigations showed that Nchwaning ore exist in different microstructure types, which could show dissimilar reduction behavior due to e.g. a differing porosity. It is further possible that a varying extent of decrepitation and disintegration occurred, which will affect the reaction rate, as the reduction rate is clearly affected by the ore size. Due to the observed variation, the apparent rate constants were determined for all parallels.

Figure 13 shows the apparent frequency factors as a function of the average particle size for A: Comilog ore and B: Nchwaning ore. For Comilog ore, it is seen that the slope is approximately -1 in both evaluated atmospheres, which correlates to the reaction rate being proportional to the inverse particle size, i.e. rate $\alpha\left(1 / r_{\mathrm{p}}\right)$. The $R^{2}$-values are high in both atmospheres, where the main contributor to the deviation is the smaller particle sizes, being either 0.50 to $1.36 \mathrm{~mm}$ or 3.33 to $4.00 \mathrm{~mm}$. Variation in the reduction rate of particles larger than
$11.2 \mathrm{~mm}$ was observed between duplicates for Nchwaning ore. This leads to less reliable estimation of the particle size effect. In Figure 13(b), frequency factors for all parallels have been included. As previously mentioned, the experiment with particle size $30-40 \mathrm{~mm}$ terminated at $1000{ }^{\circ} \mathrm{C}$ showed a large extent of decrepitation, which had altered the effective particle size during reduction. As such, it was decided to rely on the data from the experiment terminated at $800{ }^{\circ} \mathrm{C}$. Considering this, the obtained slopes are -0.75 in 80 pct $\mathrm{CO}$ and -1 in 50 pct $\mathrm{CO}$, where it is believed that the latter is more representative due to increased number of points in the regression.

\section{B. Gas Composition}

Comilog ore in particle size 11.20 to $15.00 \mathrm{~mm}$ was heated in four different $\mathrm{CO}$-concentrations in $\mathrm{CO}-\mathrm{CO}_{2}$ atmosphere, where all remaining experimental conditions remained unchanged. The frequency factors were calculated and are presented as a function of the input partial pressure of CO in Figure 14(a). It is deduced that the reaction rate is proportional to the partial pressure of $\mathrm{CO}$ of order 0.7. Particle size 0.50 to $1.36 \mathrm{~mm}$ and 3.33 to $4.00 \mathrm{~mm}$ were evaluated in two different gas compositions, which is not sufficient to estimate a linear trend. Nonetheless, the values for these particle sizes are also presented. The slopes are 0.77 and 0.78 , respectively, which shows high correlation with the relation for larger particles. The results for Nchwaning ore are shown in Figure 14(b), where particle size 11.20 to 5.00 $\mathrm{mm}$ was evaluated in three different $\mathrm{CO}$-concentrations in $\mathrm{CO}-\mathrm{CO}_{2}$ atmosphere. The slope is determined to be 1.5 , which indicates that the reaction rate is proportional to the inlet $\mathrm{CO}$ partial pressure of order 1.5. However, it may be observed that the consistency between the two parallels at 80 pct $\mathrm{CO}$ is relatively low. The values obtained for the two smaller particle sizes are also presented, where a lower dependency order 
Table II. Values Used for Description of Reaction Rate Behaviour of Comilog- and Nchwaning-Ore

\begin{tabular}{llll}
\hline & \multicolumn{1}{c}{ Description } & \multicolumn{1}{c}{ Comilog } & \multicolumn{1}{c}{ Nchwaning } \\
\hline$k_{0}$ & frequency factor & $0.53 \mathrm{~cm} / \mathrm{atm} \cdot \mathrm{min}$ & $60.4 \mathrm{~cm} / \mathrm{atm} \cdot \mathrm{min}$ \\
$E_{\mathrm{a}}$ & activation energy & $16.9 \mathrm{~kJ} / \mathrm{mol}$ & $62.6 \mathrm{~kJ} / \mathrm{mol}$ \\
$m\left(\right.$ in $\left.p_{\mathrm{CO}}^{m}\right)$ & order of CO partial pressure & 0.7 & 1.5 \\
$n\left(\right.$ in $\left.r_{\mathrm{p}}^{n}\right)$ & order of particle size & -1 & -1 \\
\hline
\end{tabular}

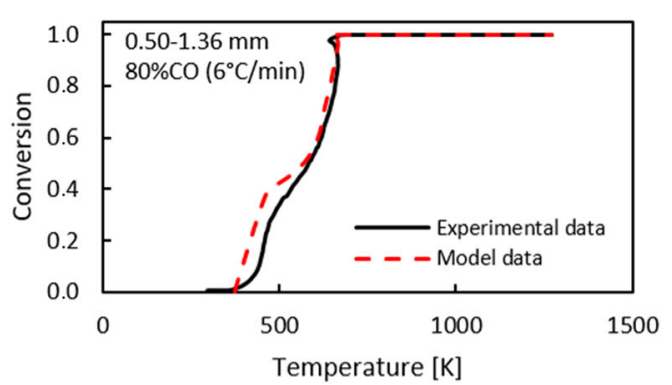

(a)

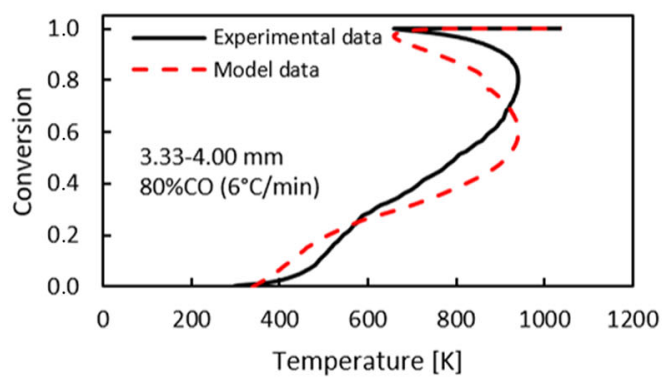

(c)

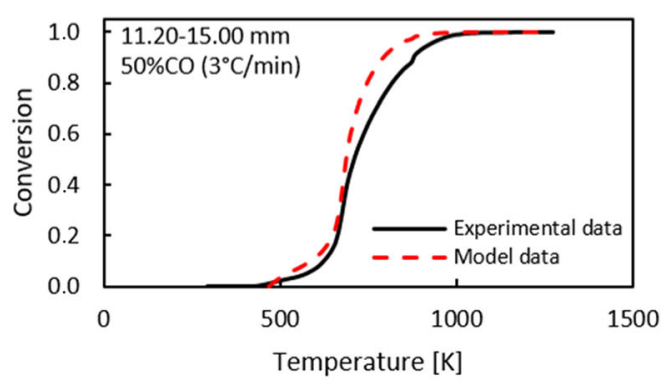

(e)

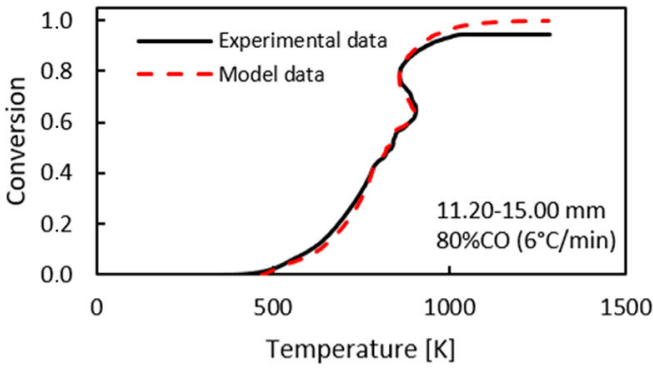

(b)

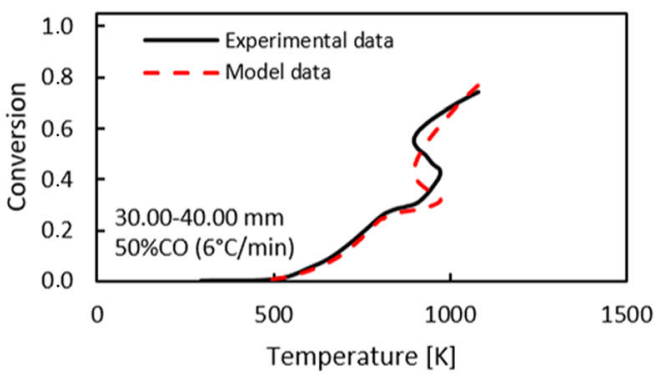

(d)

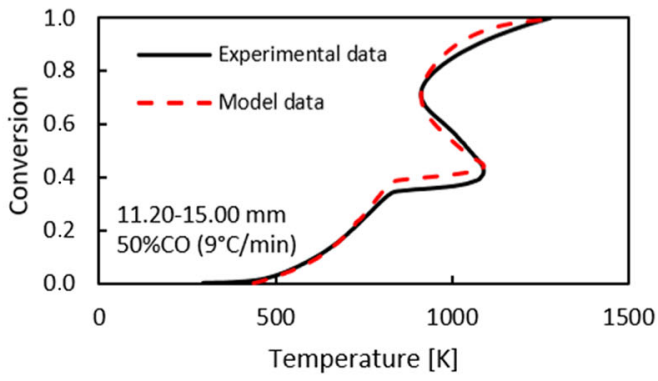

(f)

Fig. 11-Experimental- and predicted data for Comilog ore for various experimental conditions in $(a)$ to $(f)$, where conditions are marked in each figure.

is obtained. However, merely two points are used, which does not provide a valid regression, particularly considering the variation observed in the reduction behavior.

\section{Correlation to Isothermal Data}

An estimation of the activation energies at progressive conversion (reduction extent) was performed through the isoconversional method. The activation energies and correlating $\mathrm{R}^{2}$-values are shown in Figures 15 and 16 for Comilog- and Nchwaning-ore, respectively. The obtained $\mathrm{R}^{2}$-values for Comilog ore indicated a relatively good fit at all conversions, where the calculated activation energies could indicate two distinct reaction stages, where the intermediate transition stage is at conversion range 0.42 to 0.46 . The initial stage shows an average activation energy of $27.8 \mathrm{~kJ} / \mathrm{mol}$, whereas 51.3 $\mathrm{kJ} / \mathrm{mol}$ is obtained for the final stage. For Nchwaning ore, calculations were only possible up to $50 \mathrm{pct}$ conversion, due to that only two of the four evaluated temperatures resulted in a reduction extent exceeding 50 pct and a minimum of three points is required for a linear regression. In addition, the average $\mathrm{R}^{2}$-value in the initial stages $(<20$ pct) was merely 0.61 , which provides no linear trend. Calculations in conversion range 20 to 50 pct gave an average $\mathrm{R}^{2}$-value of 0.958 , 


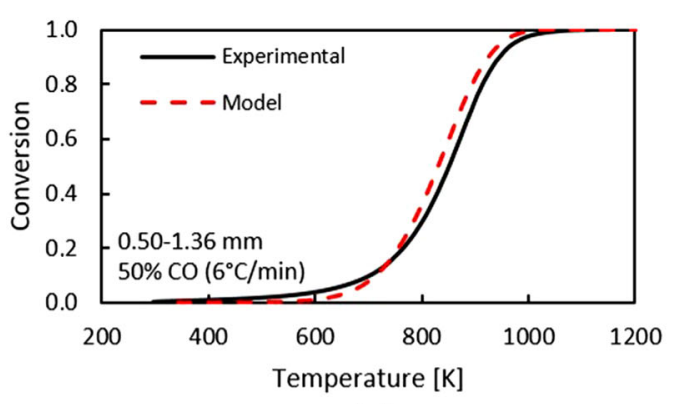

(a)

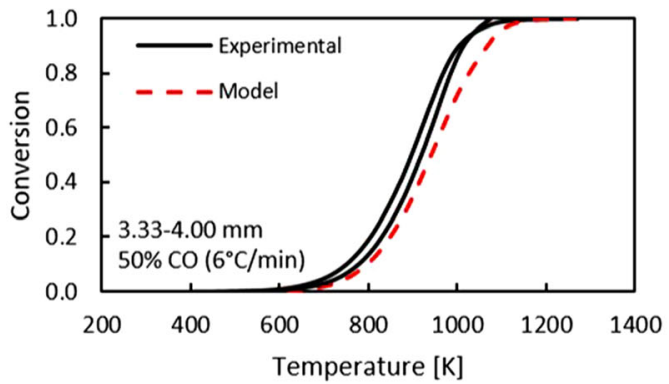

(c)

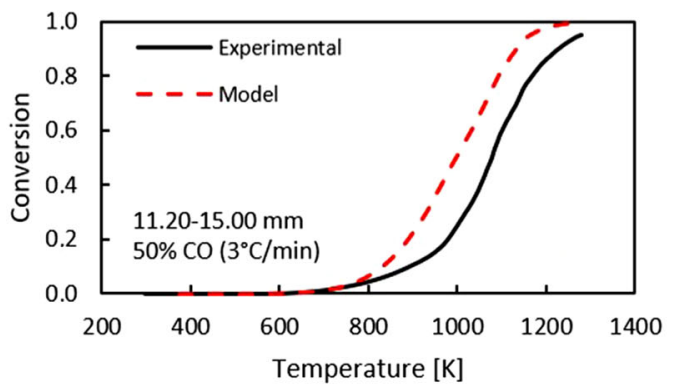

(e)

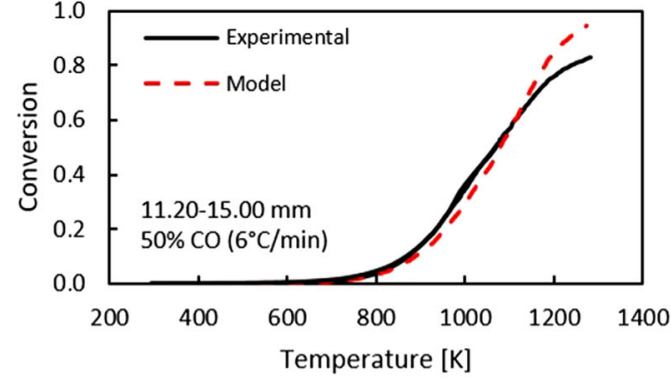

(b)

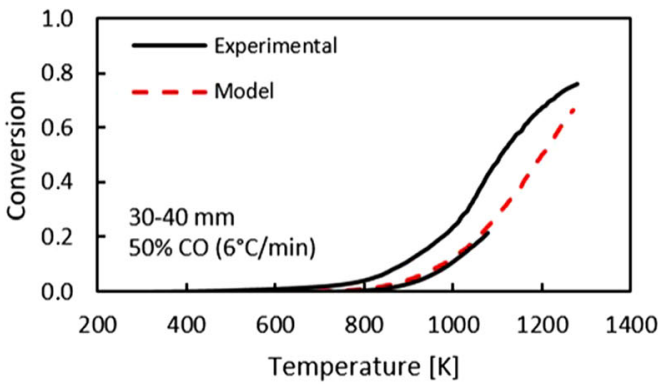

(d)

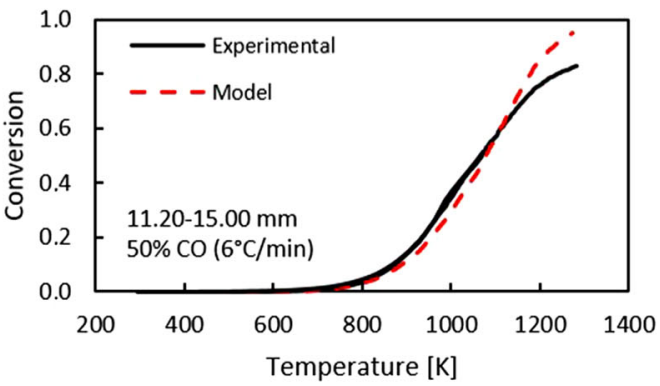

(f)

Fig. 12-Experimental- and predicted data for Nchwaning ore for various experimental conditions in $(a)$ to $(f)$, where conditions are marked in each figure.

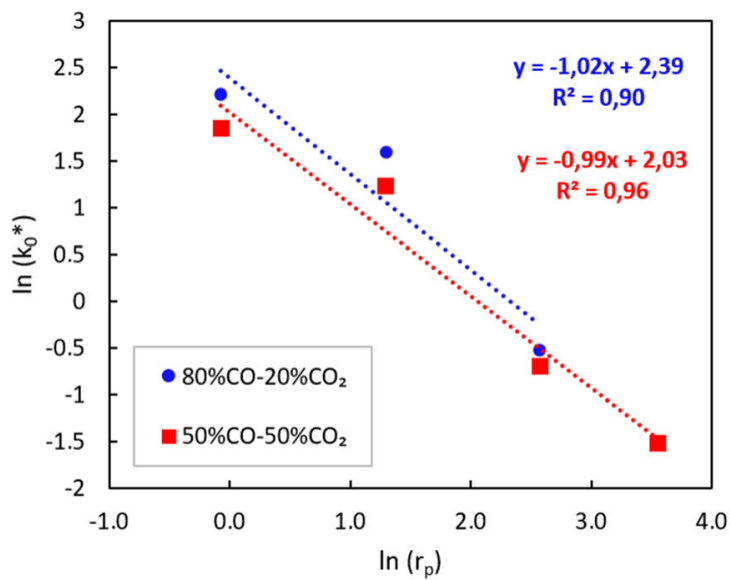

(a)

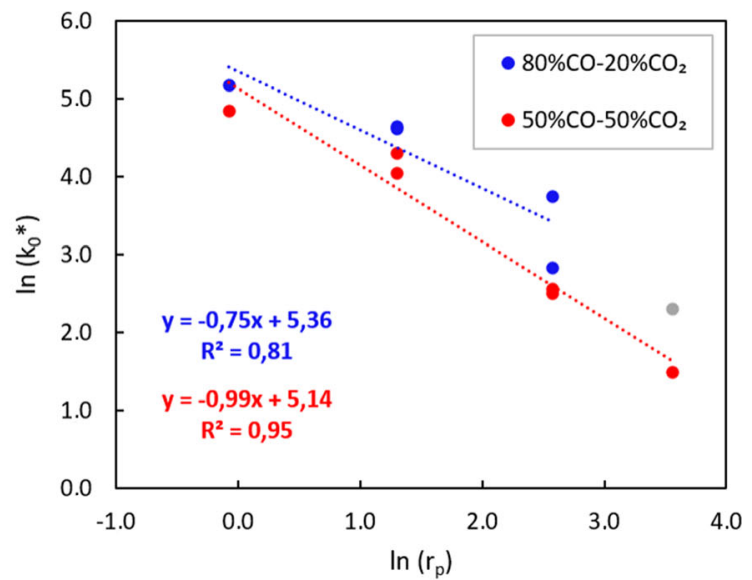

(b)

Fig. 13-Apparent frequency factors as a function of average particle size for (a) Comilog ore and $(b)$ Nchwaning ore, reduced in 50 pct $\mathrm{CO}$ or 80 pct $\mathrm{CO}$ (with remainder $\mathrm{CO}_{2}$ ). 


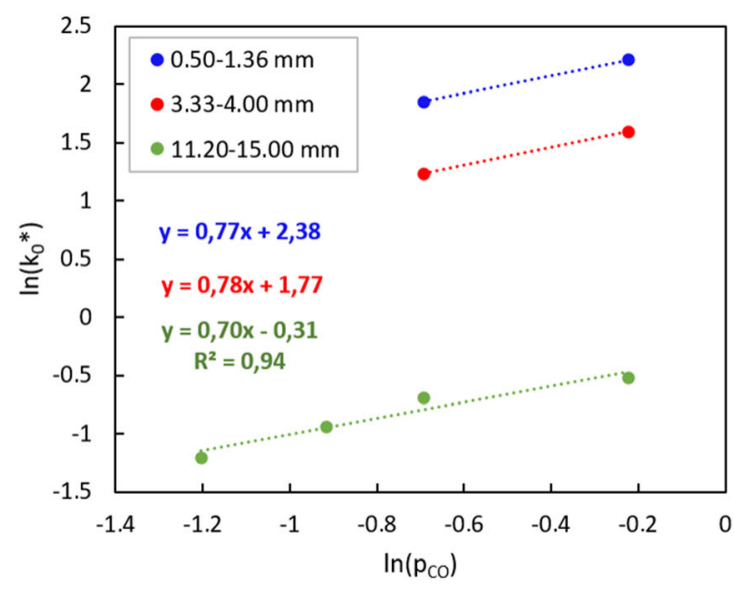

(a)

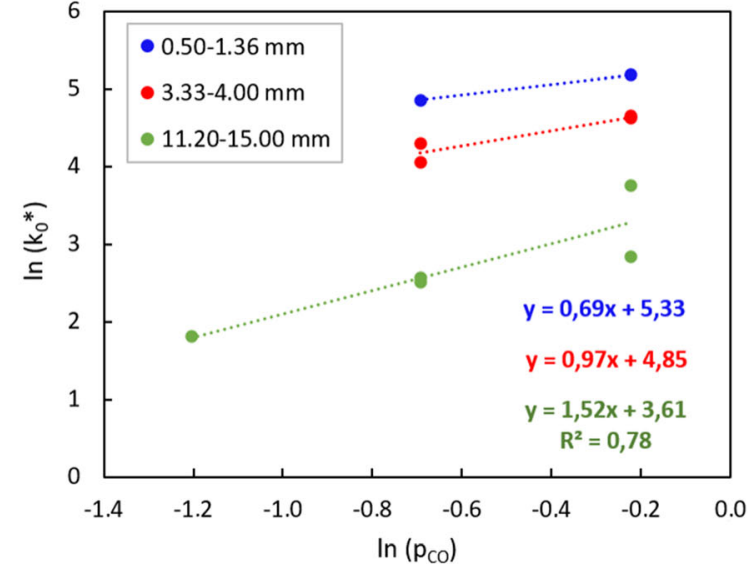

(b)

Fig. 14-Apparent frequency factors as a function of CO-concentration in feed gas for (a) Comilog ore and (b) Nchwaning ore.
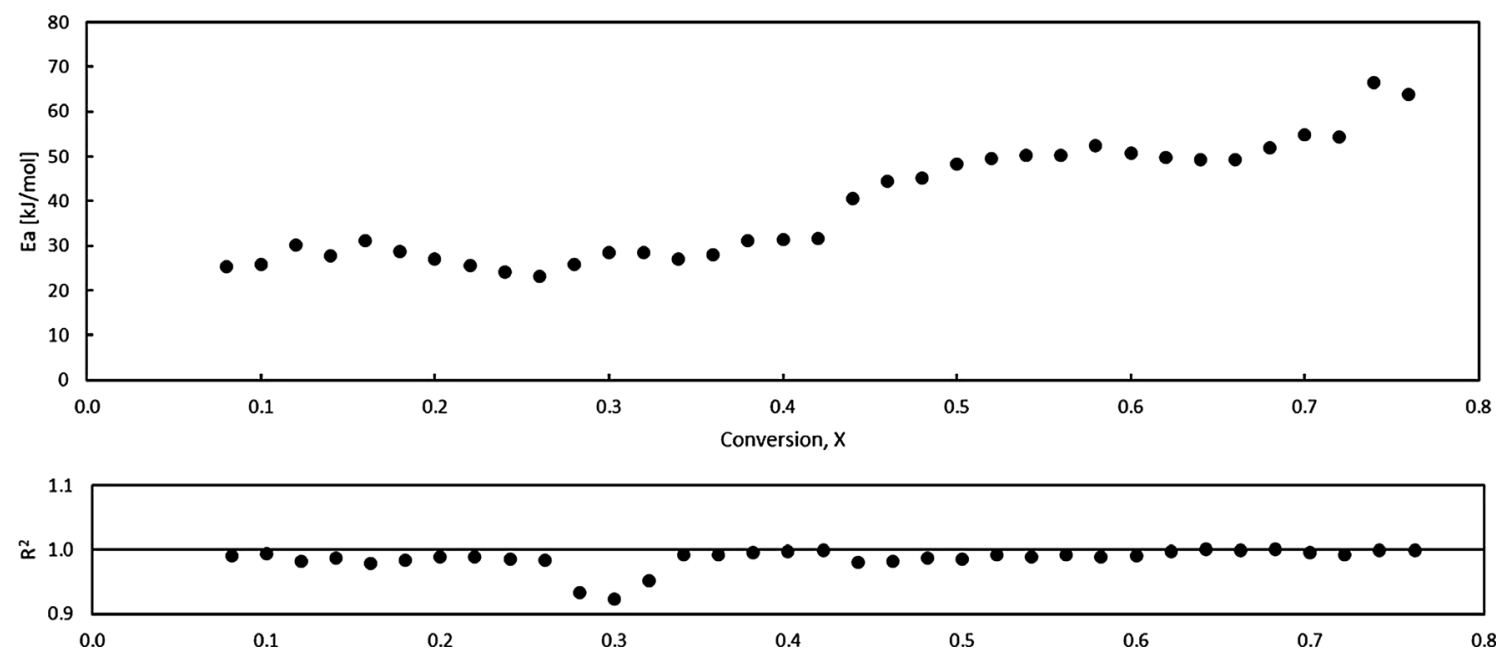

Fig. 15-Activation energies and correlating $R^{2}$-values for from the isoconversional approach for the isothermal reduction of Comilog ore in 50 pct $\mathrm{CO}$ to 50 pct $\mathrm{CO}_{2}$.
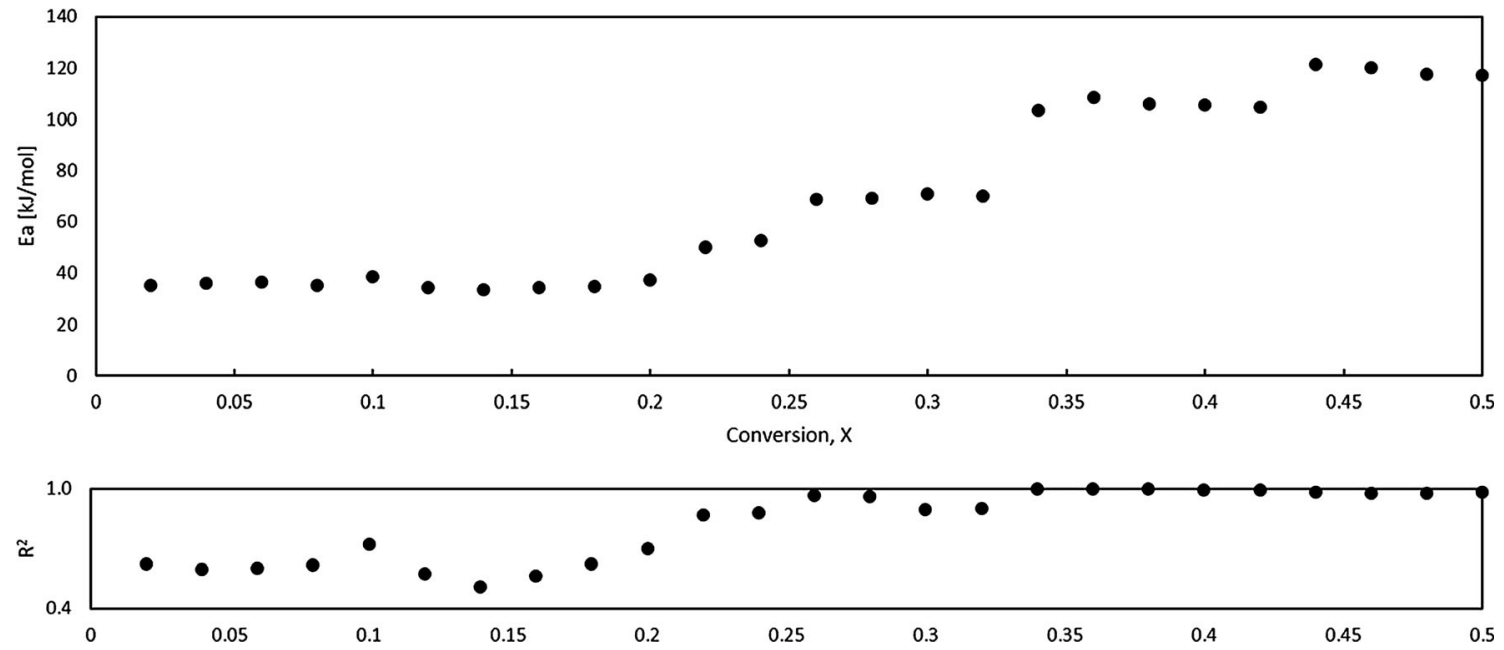

Fig. 16-Activation energies and correlating $R^{2}$-values for from the isoconversional approach for the isothermal reduction of Nchwaning ore in 50 pct $\mathrm{CO}$ to 50 pct $\mathrm{CO}_{2}$. 
which indicates more reliable values. The activation energy was found to be $60.0 \mathrm{~kJ} / \mathrm{mol}$ for 20 to $32 \mathrm{pct}$ conversion, and $111.5 \mathrm{~kJ} / \mathrm{mol}$ for 34 to 50 pct conversion. The activation energies obtained for the initial stages of reduction by the isoconversional method shows relatively high correlation to the activation energies determined from the non-isothermal data.

Another commonly used approach to analyze isothermal TGA data is the conventional model-fitting approach, where different reaction models are fitted to the experimental data, and the model giving the best statistical fit is assumed to be representative. This was performed for the data obtained for Comilog- and Nchwaning-ore in this study. It was however found that a highly similar and high degree of fit was obtained for several different models. It is hence concluded that the conventional model-fitting approach is not a valid method for deducing the reaction mechanism of manganese ore reduction.

The kinetic equation presented in Eq. [1] was obtained from the non-isothermal TGA data. The fit of these parameters to the isothermal TGA data for Comilog ore is shown in Figure 17(a). It is seen that the equation predicts a reduction extent (conversion) that is lower than the experimental values for all evaluated temperatures and holding times. It is suggested that a this may partly be explained by decrepitation, which decreases the average particle size. Decrepitation was observed in the initial stages of the experiments. Figure 17(b) shows the experimental data and the predicted conversion where the average particle size was decreased to $9 \mathrm{~mm}$ for experiments conducted at $400{ }^{\circ} \mathrm{C}$ and $500{ }^{\circ} \mathrm{C}$, and the particle size decreased to $7 \mathrm{~mm}$ at $550{ }^{\circ} \mathrm{C}$ and $600{ }^{\circ} \mathrm{C}$. This leads to a much better agreement between the curves. Figure 18 shows the experimental conversion for Nchwaning ore together with the predictions from the kinetic equation presented in Eq. [1]. A relatively low agreement is observed, particularly at high temperatures, i.e. $800{ }^{\circ} \mathrm{C}$ and $900{ }^{\circ} \mathrm{C}$. Variation between parallels was observed in the non-isothermal experiments, which were conducted with a sample size of $75 \mathrm{~g}$. As such, the isothermal experiments, which were conducted with 4 to 5 particles correlating to a total weight of ca. $20 \mathrm{~g}$, is believed to be subjected to more variation.
Hence, it is assumed that the obtained isothermal TGA curves are not representative for the overall reduction behavior.

\section{DISCUSSION}

A relatively good agreement was obtained between Eq. [1] and the non-isothermal experimental data. The equation that was developed in this study describes the overall reduction rather than the governing mechanisms. It also describes a multistep reaction mechanism as a single step. In spite of this, the equation was able to predict the reduction extent of the ores with a reasonably well agreement.

The reduction rate of both Comilog- and Nchwaning-ore was found to be proportional to the inverse particle size. For topochemical reaction mechanisms, this would correlate to a chemical reaction control. However, this relation is valid for ideal samples of zero initial porosity, which is clearly not the case of manganese ores. Furthermore, the results presented by Larssen $^{[12]}$ indicated that neither ore displayed a shrinking core behavior during reduction. Varying the particle size fraction of manganese ores will alter not only the available surface area, but also additional factors. It is

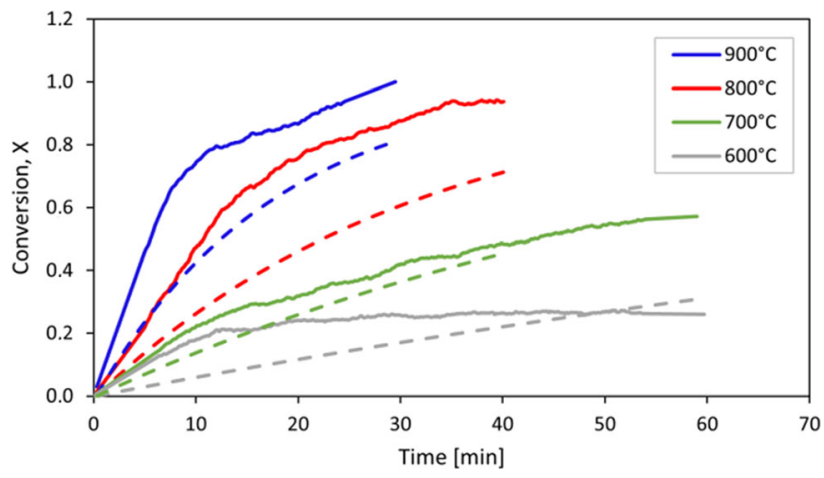

Fig. 18-Model parameters found from non-isothermal TGA data used to model isothermal reduction data for Nchwaning ore for 13.1 $\mathrm{mm}$ particles.

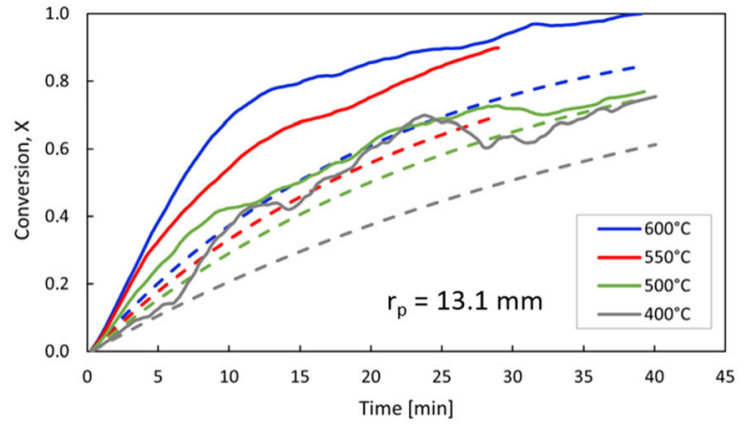

(a)

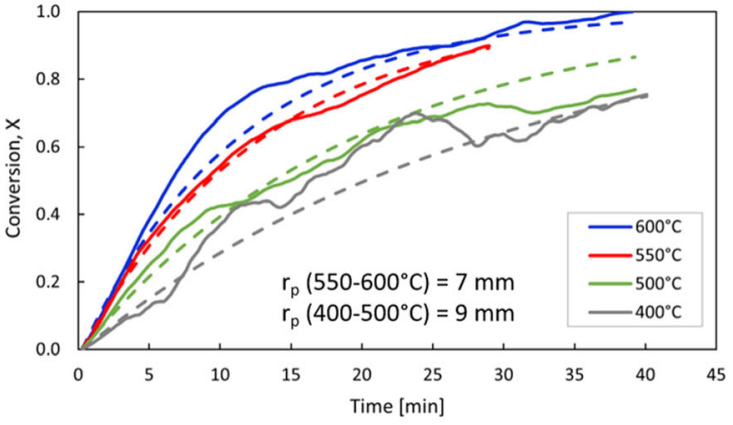

(b)

Fig. 17-Fit of kinetic parameters obtained from non-isothermal TGA data applied to isothermal TGA data for Comilog ore. (a) fit of initial average particle size $(13.1 \mathrm{~mm}),(b)$ average particle size was decreased from 13.1 to $9 \mathrm{~mm}$ for TGA data obtained at $400{ }^{\circ} \mathrm{C}$ and $500{ }^{\circ} \mathrm{C}$ and decreased from 13.1 to $7 \mathrm{~mm}$ for data obtained at $550{ }^{\circ} \mathrm{C}$ and $600{ }^{\circ} \mathrm{C}$. 
well known that manganese ores decrepitate when heated in reducing atmosphere. This implies that the ores do not remain in the initial particle size throughout the reduction course, and the extent at which the effective particle size decreases may be more severe for larger particles. Further, a changing particle size may affect the heat transfer effects and temperature gradients both within single particles and clusters. ${ }^{[16]}$ Hence, the obtained relation between the average particle size and the reaction rate should rather be viewed as an average dependency on the combined geometrical effects. A few investigations are available where the ore has been evaluated in several size fractions. Pochart et al. ${ }^{[7]}$ determined the reduction extent at $1100{ }^{\circ} \mathrm{C}$ after non-isothermal heating in $\mathrm{CO}-\mathrm{CO}_{2}$ atmosphere and found the reduction extent to be larger for smaller particles compared to larger. While the effect was not quantified, the increase was of similar magnitude for Comilog- and Nchwaning-ore, which correlates with the observations made in this study. A promoted reduction with decreasing particle size have also been observed by others. ${ }^{[3,17]}$ From reduction experiments performed with calcined ore, $\mathrm{Gao}^{[4]}$ observed no effect with changing the particle size, however, the evaluated sizes were all within $<45 \mu \mathrm{m}$ to $500-1000 \mu \mathrm{m}$, which may all be considered as fines.

Both ores were affected by the CO-concentration in $\mathrm{CO}-\mathrm{CO}_{2}$ atmosphere, where Nchwaning ore was found to be more sensitive. The quantified dependencies were of order 0.7 and 1.5 for Comilog- and Nchwaning-ore, respectively. The difference may potentially be linked to the ores' porosity, where Comilog is known to be a porous ore and Nchwaning has insignificant initial porosity. ${ }^{[5]}$ An increased reduction rate of manganese ores with increasing $\mathrm{CO}$-concentration in $\mathrm{CO}-\mathrm{CO}_{2}$ atmosphere has also been observed by others. ${ }^{[1,3,4]} \mathrm{A}$ few publications have also shown that the gas flow may be the limiting factor, particularly for Comilog ore in its initial reduction stages, which obtains a considerably fast reaction rate. ${ }^{[7,18]}$ These studies were conducted with a similar total gas flow as in the present study, however a considerably larger sample size coupled with a high heating rate was used.

An activation energy of $17 \mathrm{~kJ} / \mathrm{mol}$ was estimated for Comilog ore, whereas $63 \mathrm{~kJ} / \mathrm{mol}$ was found for Nchwaning ore. The reduction of Nchwaning ore is initiated at a higher temperature compared to Comilog ore. This may largely be related to that Comilog is largely composed of $\mathrm{MnO}_{2}$-oxides, whereas Nchwaning ore contains $\mathrm{Mn}_{2} \mathrm{O}_{3}$ oxides. By comparing the theoretical increase in the reaction rate at the given activation energies with the experimentally observed reaction rates, it is seen that the activation energies successfully describe the temperature dependency of the ore reduction. Previously reported activation energies indicate that the activation energy varies with the investigated material and/or the experimental conditions. Nonetheless, the activation energies determined in this study are of similar magnitude of those previously reported. $[1,3,11,19]$
The information obtained through conventional gas-solid reaction analysis tools for isothermal data is scarce. Activation energies obtained through the isoconversional approach in the initial reaction stages were however of similar magnitude as the activation energies obtained through model-fitting of non-isothermal data. The conventional model-fitting approach used to estimate a governing reaction mechanism provided a high degree of statistical fit for several different reaction models. This may be related to that several reactions occur simultaneously in reduction of manganese ore. Furthermore, a large contributing factor to unreliable/ non-representative data is obviously the heterogeneity of the ores, in combination with the small sample sizes utilized in the experiments, particularly for Nchwaning ore.

The gas-solid reduction of manganese ores in the prereduction zone of an industrial ferromanganese furnace is vital to the efficiency of the overall process, both in terms of carbon- and energy consumption. The optimization potential lies within ensuring a complete prereduction of the manganese ores used as raw materials at temperatures below $800^{\circ} \mathrm{C}$. In order to achieve this, representative information on the factors affecting the prereduction of various manganese ores is required. The results presented in this study represents a step towards an increased understanding of the prereduction zone by quantifying the effect of particle size, furnace gas composition and temperature.

\section{CONCLUSIONS}

Thermogravimetric data was obtained for the reduction of Comilog- and Nchwaning-ore in $\mathrm{CO}-\mathrm{CO}_{2}$ atmosphere. Investigated variables were temperature, particle size and $\mathrm{CO}$-concentration. The reduction of Comilog and Nchwaning manganese ores were analyzed by gas-solid reaction tools. A kinetic equation was developed, which was found to produce a reasonably well agreement with the experimental reduction behavior. The model described the overall reduction trends rather than the governing mechanisms. The reduction rate of both ores was proportional to the inverse average particle size fraction. An increasing partial pressure of $\mathrm{CO}$ in $\mathrm{CO}-\mathrm{CO}_{2}$ atmosphere promoted the reaction rate with an order of 0.7 and 1.5 for Comilog and Nchwaning ore, respectively. An activation energy of $17 \mathrm{~kJ} / \mathrm{mol}$ was estimated for Comilog ore, whereas $63 \mathrm{~kJ} / \mathrm{mol}$ was found for Nchwaning ore.

\section{ACKNOWLEDGMENTS}

This work has been funded by HighEFF - Centre for an Energy Efficient and Competitive Industry for the Future, an 8-year Research Centre under the FME-scheme (Centre for Environment-friendly Energy Research, 257632). The authors gratefully acknowl- 
edge the financial support from the Research Council of Norway and user partners of HighEFF.

\section{FUNDING}

Open access funding provided by NTNU Norwegian University of Science and Technology (incl St. Olavs Hospital - Trondheim University Hospital).

\section{OPEN ACCESS}

This article is licensed under a Creative Commons Attribution 4.0 International License, which permits use, sharing, adaptation, distribution and reproduction in any medium or format, as long as you give appropriate credit to the original author(s) and the source, provide a link to the Creative Commons licence, and indicate if changes were made. The images or other third party material in this article are included in the article's Creative Commons licence, unless indicated otherwise in a credit line to the material. If material is not included in the article's Creative Commons licence and your intended use is not permitted by statutory regulation or exceeds the permitted use, you will need to obtain permission directly from the copyright holder. To view a copy of this licence, visit http://creativec ommons.org/licenses/by/4.0/.

\section{REFERENCES}

1. K.L. Berg: The Norwegian University of Science and Technology, 1998 .
2. M. Tangstad, S. Wasbø, and R. Tronstad: in Conference proceedings, Infacon IX (Quebec), 2001, pp. 202-07.

3. R.J. Ishak: Reaction Kinetics for Reduction of Manganese Ore with Carbon Monoxide in the Presence of Carbon. Dr. Ing thesis, NTNU, 2002.

4. Y.B. Gao, H.G. Kim, and H.Y. Sohn: Miner. Process. Extr. Metall, 2012, vol. 121, pp. 109-16.

5. K. Turkova, D. Slizovskiy, and M. Tangstad: ISIJ international, 2014, vol. 54, pp. 1204-08.

6. M. Visser, H. Smith, E. Ringdalen, and M. Tangstad: in The thirteenth International Ferroalloys Congress, INFACON XIII, Kazakhstan, 2013. https://www.pyrometallurgy.co.za/Infacon XIII/0553-Visser.pdf.

7. G. Pochart, L. Joncourt, N. Touchard, and C. Perdon: World, 2007, vol. 800, p. 1200.

8. R. Ishak and M. Tangstad: INFACON XI, 2007, pp. 268-79.

9. K.L. Berg and S.E. Olsen: Metall. Trans. B, 2000, vol. 31, pp. 47790.

10. H.E. Barner and C.L. Mantell: Ind. Eng. Chem. Process. Des. Dev., 1968, vol. 7, pp. 285-94.

11. T.J.W. De Bruijn, T.H. Soerawidjaja, W.A. De Jongt, and P.J. Van Den Berg: Chem. Eng. Sci., 1980, vol. 35, pp. 1591-99.

12. T.A. Larssen, D. Senk, and M. Tangstad: Metall. Trans. B, h ttps://doi.org/10.1007/s11663-020-02018-0.

13. T.A. Larssen, M. Tangstad, and I.T. Kero: in Extraction 2018, Springer, Berlin, 2018, pp. 1093-1101

14. P. Kowitwarangkul, A. Babich, and D. Senk: Steel Res. Int., 2014, vol. 1, pp. 611-22.

15. Outotec: HSC Chemistry Version 10, 2021.

16. M. Ksiazek, M. Tangstad, and E. Ringdalen: Southern African Pyrometallurgy 2011.

17. O. Biørnstad: Decrepitation of Comilog, Assmang and UMK manganese ores during prereduction. MSc thesis, NTNU, 2020.

18. D. Ngoy: Pre-Reduction of Manganese Ores with $\mathrm{CO}$ and $\mathrm{H}_{2} \mathrm{Gas}$, NTNU, 2019

19. A.A. El-Geassy, M.I. Nasr, M.A. Yousef, M.H. Khedr, and M. Bahgat: Ironmak. Steelmak., 2000, vol. 27, pp. 117-22.

Publisher's Note Springer Nature remains neutral with regard to jurisdictional claims in published maps and institutional affiliations. 